\title{
Scientific journals and conflict of interest disclosure: what progress has been made?
}

\author{
Kathleen Ruff
}

\begin{abstract}
The article addresses the failure of the scientific community to create an effective mechanism to protect the integrity of the scientific literature from improper influence by vested interests. The seriousness of this threat is increasingly recognized. Scientists willing to distort scientific research to serve vested interests receive millions of dollars for their services. Organizations such as the International Committee of Medical Journal Editors, the World Association of Medical Editors and the Committee on Publication Ethics (COPE) have launched initiatives to establish international standards for Conflict of Interest (COI) disclosure. COPE requires its 7,000 member journals to comply with its Code of Conduct for Journal Editors. While these initiatives are encouraging, they are internal educational endeavours only. Five examples are given showing failure of COPE member journals to comply with COPE's Code of Conduct. While COPE offers a complaint process, it involves only discussion and voluntary compliance. COPE neither polices nor enforces its Code. Instead of the current feeble, un-resourced process, which delivers neither transparency nor accountability, the article proposes the creation of a mechanism that will employ specific, effective measures to address contraventions of $\mathrm{COI}$ disclosure requirements.
\end{abstract}

Keywords: Industry influence, Conflict of interest disclosure, Publication ethics, Enforcement mechanism

\section{Background}

In its 2010 Science Report [1] UNESCO noted the growing concern about conflict of interest (COI) in scientific journals. UNESCO cited a call for scientific journals to adopt a common standard regarding "the complex and growing financial arrangements that have developed in recent years between vested interests and independent scientists [2]."

Clear evidence exists that industry funding can and does influence research findings. An analysis by vom Saal and Welshons for example, showed that 11 out of 11 industryfunded studies found bisphenol A (BPA) had no significant action, while 109 of 119 studies that had no industry funding (92\%) did find effects of BPA [3].

Some steps have been taken to require disclosure of industry and other funding. The International Committee of Medical Journal Editors (ICMJE) has produced a standard Disclosure of Conflicts of Interest Form [4] which ICMJE member journals require authors to use.

The World Association of Medical Editors (WAME) has highlighted the need for journals to take action

Correspondence: kruff@bulkley.net

Rideau Institute, 63 Sparks, Suite 608, Ottawa, ON K1P 5A6, Canada regarding the issue of COI: "If COI is not managed effectively it can cause authors, reviewers, and editors to make decisions that, consciously or unconsciously, tend to serve their competing interests at the expense of their responsibilities in the publication process, thereby distorting the scientific enterprise. This consequence of COI is especially dangerous when it is not immediately apparent to others. In addition, the appearance of COI, even where none actually exists, can also erode trust in a journal by damaging its reputation and credibility [5]".

In 2010 the 2nd World Conference on Research Integrity approved a Position Statement, Responsible research publication: international standards for authors [6]. The Committee on Publication Ethics (COPE) described these as the first universal global guidelines for authors from all areas of scholarly publishing. COPE urged all editors to incorporate these standards into their editorial policies and instructions for authors [7]. In December 2013, as a joint endeavour to promote a common standard regarding COI disclosure, WAME, COPE, the Directory of Open Access Journals, and the Open Access Scholarly Publishers Association published The Principles of Transparency and Best Practice in Scholarly Publishing [8]. 
COPE has adopted a Code of Conduct for Journal Editors with which it requires in theory, its 7,000 member journals to comply [9]. COPE recommends that, if a conflict of interest comes to light after publication of an article, the journal should publish a Correction disclosing the conflict of interest. COPE provides a complaint mechanism regarding contraventions of its Code of Conduct [10]. It also has enforcement ability, although a weak one. If a COPE member is not willing to comply with its Code of Conduct, COPE "will aim to discuss that with the member, and will ask them to consider their membership of the organization."

These provisions imply that COPE enforces its Code.

At face value it appears that progress has been made. In the cases below, however, involving five COPE member journals, these policies were disregarded. Even when COPE concluded that a complaint regarding undisclosed conflict of interest was substantiated and recommended that the journal involved publish a Correction in compliance with COPE's policy, COPE categorically notified the journal that it was free to disregard COPE's recommendation and continue as a COPE member without any consequences.

Thus COPE does not require its member journals to comply with its Code. COPE has never used its enforcement ability and has never asked a journal to withdraw its membership of COPE. Furthermore apart from COPE, the scientific community has created no mechanism to address COI disclosure violations. COPE is the only recourse available.

\section{1) Annals of occupational hygiene}

In 2011 and 2012 the Annals of Occupational Hygiene $(\mathrm{AOH})$ published two papers on research, financed by Georgia Pacific Corporation (GP) regarding asbestoscontaining joint compound that the company had sold in the past $[11,12]$. The company was facing court cases involving nearly $\$ 1$ billion in liability related to this product.

Three of the five authors of the two articles worked for Exponent and one was an employee who GP deliberately transferred for the purpose of carrying out the research, to be under the control of GP's litigation department.

David Michaels has described Exponent as one of the premier firms in the product defense business. These firms "profit by helping corporations minimize public health and environmental protection and fight claims of injury and illness. (...) This is science for hire period, and it is extremely lucrative," states Michaels [13].

In June 2013 a New York court ruled that the two papers, and six additional similar articles financed by GP, constituted potential crime-fraud [14]. The court stated that GP had commissioned the research with the intent of casting doubt on the capability of chrysotile asbestos to cause cancer, planned to use the articles to assist its litigation efforts, that GP's lawyers had significant input in the content, reporting of the results and prepublication review process of the articles, and that the articles failed to disclose the participation of the company lawyers.

Article 2.1 of COPE's Code of Conduct requires that readers be informed whether the funder of the research had any role in the research and its publication and if so, what this was [9]. The $\mathrm{AOH}$ articles violate this requirement. They do not disclose that the company's litigation department had control over the work nor that one of the authors had been transferred so as to be under the direction of GP's litigation department.

The role of a litigation department is not to be impartial or independent. Its purpose is to do everything possible to defend the company's interests.

These are improprieties of an extremely serious character. The $\mathrm{AOH}$ should have withdrawn the articles or at the very least, required publication of an Erratum in compliance with COPE's Article 2.1, to disclose that the study was not a normal study, but controlled by GP's litigation department, with the research data thus rendered inaccessible under lawyer-client privilege. This is the opposite of transparent scientific research.

The $\mathrm{AOH}$ did not do so. Instead the article remains on the $\mathrm{AOH}$ website with no conflict of interest statement from the authors disclosing their own and their consulting companies' financial ties to Georgia Pacific. No information is provided to readers regarding the improprieties involved in the article. The reader thus assumes that the article complies with COPE's Code of Ethics, which it does not.

The chief editor of the AOH Noah Seixas, published a commentary, Protecting Our Science, stating that through reviewing the GP decision, it had become clear that the $\mathrm{AOH}$ should strengthen its procedures regarding COI [15]. The AOH will monitor the results of the litigation involving the GP research, Seixas wrote, and "If the court finds evidence of fraud in the production of the research reported in our pages, we will act on these findings in accord with the COPE guidelines for ethical publication."

Of course the $\mathrm{AOH}$ should take action in accord with the COPE guidelines in the face of evidence of research fraud. And it is commendable that the $\mathrm{AOH}$ is discussing these issues and plans to adopt stronger COI disclosure standards. Seixas avoids the question however, as to why the $\mathrm{AOH}$ took no action to address the non-compliance with the COPE Code of Conduct-a Code the $\mathrm{AOH}$ says it follows.

\section{2) Current opinion in pulmonary medicine}

In July 2014 the journal Current Opinion in Pulmonary Medicine (COPM) published an article by David Bernstein, Health Risks of Chrysotile Asbestos [16], which stated: "There are no conflicts of interest." 
The journal's disclosure form [17] specifically requires authors to state "relevant financial activities outside the submitted work". Bernstein did not comply with this requirement and indicated that he had no such activities. This is untrue. For more than a decade his work has been funded by asbestos industry organisations such as the Chrysotile Institute and the International Chrysotile Association. Over the past several years, Bernstein has been continuously financed by the asbestos industry to write articles and make presentations promoting use of chrysotile asbestos in Brazil, China, Colombia, India, Indonesia, Korea, Mexico, Quebec, Russia, South Africa, Thailand, Vietnam, Malaysia, the Philippines, Ukraine and Zimbabwe.

In COPM Bernstein stated that he received no funding for his article. The article, however, relied on and cited Bernstein's asbestos industry financed articles, which Bernstein self-praised as being "of outstanding importance". COPM thus acted as a conduit for undeclared asbestos industry financed work which promoted the industry's interests.

A complaint was submitted to the editors and publisher that Bernstein had contravened the journal's COI disclosure requirements by failing to disclose his intimate long-standing and continuing financial ties to the asbestos industry [18]. In response to the complaint, the publisher stated: "We will publish an erratum that states he (Bernstein) is a paid consultant to the chrysotile asbestos industry and name the commercial organisations he has been paid by in the last 36 months."

The journal then published the following Erratum:

"The health risk of chrysotile asbestos: Erratum

During the editing process of the recent article by Bernstein [1] the conflicts of interest statement was wrongly amended from 'No conflicts of interest relevant to this article' to 'There are no conflicts of interest.' The publisher apologises for this error. Dr Bernstein would like to take this opportunity to clarify that he works as a scientific consultant to the chrysotile asbestos industry and gives presentations worldwide on the science of chrysotile asbestos. In the last three years he has received payment for his consultancy services from: Honeywell International, Chrysotile Association and Zimbabwe National Chrysotile Taskforce.

Dr Bernstein received no payment compensation or funding for the current article [1]. The article is solely his work and the opinions stated therein are his own.

[1] Bernstein DM. The health risk of chrysotile asbestos. Curr Opin Pulm Med. 2014; 20:366-370.”

The implied interpretation put forward by the publisher, that only payments made for work conducted for the single particular article constitute COI, guts any meaningful
COI disclosure; it violates the journal's COI disclosure form, which requires authors to disclose financial activities "outside the submitted work"; and it flaunts the ICMJE's COI standard that authors must disclose "interactions with ANY entity that could be considered broadly relevant to the work." [3].

\section{3) Critical reviews in toxicology}

In 2013, Bernstein and co-author Jacques Dunnigan published a review article, Health Risks of Chrysotile Revisited [19], in Critical Reviews in Toxicology (CRT). They stated that the preparation of the review was funded by a grant from two asbestos industry organisations, the International Chrysotile Association (ICA) and the Chrysotile Institute. This statement was untrue. In a court deposition, the president of the ICA, Bob Pigg, stated that no grant existed. Instead, court documents show that Bernstein submitted invoices of approximately US $\$ 2,800$ per-diem to the ICA for "services rendered" in writing the manuscript. In total, the ICA paid US $\$ 179,306.51$, almost all of which was paid to Bernstein, with a small amount going to Dunnigan, for the writing of the article.

The Declaration of interests stated that Bernstein had appeared as an expert witness in litigation concerned with "alleged health effects of exposure to chrysotile" and Dunnigan had served as an expert witness on the health effects of chrysotile before the Workers Compensation Board of Québec. The authors did not disclose the extensive financing they receive as consultants to the asbestos industry.

The publisher of the journal, Informa Pharmaceutical Science, requires "full disclosure of all financial, consulting, and personal relationships that could be viewed as presenting a potential conflict of interest [20]." Furthermore, Informa states that "If any potential conflicts of interest are found to have been withheld following publication, the journal will proceed according to COPE guidance."

Several scientists submitted a complaint to the editor of the journal, pointing out that the authors had violated the journal's COI requirements [21]. The editor did not respond and took no action.

Clearly, the COI policy of Critical Reviews in Toxicology is excellent on paper. In practice, however, it was disregarded.

\section{4) International journal of environmental research and public health}

In 2013, the International Journal of Environmental Research and Public Health (IJERPU) published an article, Domestic Asbestos Exposure: A Review of Epidemiologic and Exposure Data [22]. Three of the authors were employees of the consulting company, Exponent. The fourth, 
David Dahlstrom, a former Exponent employee, now has his own consulting company.

Between 2001 and 2009, three auto companies (Chrysler, Ford and GM) paid Exponent over 26 million dollars to help them defeat claims by mechanics and family members regarding asbestos-related disease.

In the article in the IJERPU, the authors stated under Conflicts of Interest: "No funding was obtained to prepare this manuscript. Two of the authors (David L. Dahlstrom and Fionna Mowat) have been designated as experts in litigation matters related to asbestos, and all authors have been retained as consultants in asbestos-related litigation matters."

Thus, apparently, the authors carried out this work pro bono. The article was conspicuously tailored to meet the exact needs of auto companies facing litigation on this issue and its conclusions were beneficial to these companies' litigation activities: "These results provide support that brake dust derived from chrysotile containing brake drums would not initiate a pathological response in the lung following short term inhalation."

Under its Potential COI requirements, the IJERPU states that "Financial support for the study must be fully disclosed." The publication fee for the article to be published in this open access journal was $\$ 1,750$. The authors did not disclose who paid the fee.

When asked, Dahlstrom, said that he did not know who paid the fee for his article to be published, but felt confident that Exponent had paid. A request was made to Dahlstrom that, in the interest of transparency, he and his co-authors publish a Correction in the IJERPU to disclose who paid the fee for publishing their manuscript and whether the payer had any COI.

Dahlstrom refused. Requests to the corresponding author of the article, Emily Goswami, and to the Editor-inChief of the journal, Paul B. Tchounwou, were met with silence.

The publisher of the journal, MDPI AG in Switzerland, responded saying: "We are a member of COPE and refer to their guidelines and advice when cases that are not clear-cut come up. Payment of article processing fees would be considered as financial support for the research, so any conflict of interest between the funder and the research topic should be declared."

When requested to disclose who paid the publication fee for the article and whether the payer had any COI, MDPI AG refused, however, to do so. "Authors need only acknowledge external funding sources," said MDPI AG. "Funding by the authors themselves or their employer does not need acknowledgment, as it doesn't add an additional stakeholder."

Thus the payer of the publication fee remains anonymous. Readers are not informed whether Exponent paid its employees to write the article, and whether Exponent paid the publication fee. They are not informed that Exponent has received multi-million dollar contracts from auto companies that derived a benefit from the article.

\section{5) European journal of cancer prevention}

In its May 2012 issue, the European Journal of Cancer Prevention (EJCP) published an article by Carlo La Vecchia and Paolo Boffetta, Role of stopping exposure and recent exposure to asbestos in the risk of mesothelioma [23]. La Vecchia is an Associate Editor of the journal.

The EJCP states the following: "Conflicts of Interest. Authors must state all possible conflicts of interest in the manuscript, including financial, consultant, institutional and other relationships that might lead to bias or a conflict of interest [24]."

The authors stated they had no conflict of interest, when they had, in fact, been paid by companies facing criminal charges for asbestos-related deaths of workers from mesothelioma. In March 2011 and July 2011 they advanced in courts, as expert witnesses for the defence, the same arguments they put forward in the article they submitted to the EJCP in September 2011. As soon as the print proofs of the EJCP paper became available in November 2011, the company lawyers submitted them as evidence for the defence. These arguments enabled the current company managers to have impunity for the deaths of the workers.

The authors stated that the Italian Cancer Research Association (AIRC) had funded the article. This was untrue. AIRC confirmed that it had provided no funding for the article.

The Editor-in-Chief of the journal, Jaak Janssens, rejected the complaint, saying that the authors had reaffirmed that they had no COI. The Associate Editor, J. Bogers, stated: "I don't really understand this complaint. I still don't see the conflict of interest, especially reading the content of the paper again."

In March 2014, a complaint was submitted to COPE [25], pointing out that the journal had contravened specific provisions of COPE's Code of Conduct by failing to disclose COI; that the Editor-in-Chief had no known expertise on the asbestos issue but had approved the article in four days, which constituted an improper peer review process; that no policies were in place for handling submissions from an Associate Editor to ensure unbiased review; that the journal had not corrected the inaccurate funding information; that the journal did not have a system for managing board members' conflicts of interest and did not publish a list of board members' relevant financial and other interests.

On October 6, 2014, COPE informed the journal that the information indicated that the authors had a COI, which should have been declared. COPE recommended that the journal publish a Correction in line with COPE's guidelines [26]. 
On October 14, Phil Daly, Senior Publisher, Medical Journals, at Wolters Kluwer, informed COPE and the complainants: "We are following your recommendation and we are preparing a note for publication that addresses these issues."

In December 2014, the EJCP published the following Erratum [27]:

\section{"Role of stopping exposure and recent exposure to} asbestos in the risk of mesothelioma: Erratum

European Journal of Cancer Prevention 2015, 24:68 The authors would like to bring the reader's attention the conflicts of interest for their review paper ( $\mathrm{La}$ Vecchia and Boffetta, 2012), and subsequent correspondence (La Vecchia and Boffetta, 2014). La Vecchia has acted as expert witness for the defendants or the judge in criminal trials involving occasional exposure to asbestos, on behalf of ENEL (Rome, Italy), Edison (Milan, Italy), Pirelli Tyres (Milan, Italy) and the Ordinary Tribunal of Turin (Italy). Boffetta has acted as expert witness for the defendants in a criminal trial involving exposure to asbestos in the manufacture of synthetic polymers and risk of mesothelioma (Edison, Milan, Italy).

This work was not conducted with the contribution of the Italian Association for Cancer Research as stated on page 229 and the authors withdraw this statement on the acknowledgement of funding."

When asked what action will be taken with regard to the other issues raised in the complaint, Daly stated: "During our review, in addition to those points mentioned previously, we have raised the awareness on conflicts of interest. We have met some of the editors and have other communication and educational recommendations (e.g. COPE's eLearning modules) planned, and that we will follow these up on a regular basis."

It is a positive outcome that, as a result of the complaint filed with COPE, the EJCP finally published the Erratum and is undertaking educational activities for the journal's editors re COI, education that is clearly much needed. The publisher deserves credit for taking action to comply with COPE's standards, for publishing an Erratum that addresses the COI issue clearly and for requiring the authors to accept responsibility for correcting their undeclared COI.

Relying on individuals to devote a year of continuous effort to persuade a COPE member journal to comply with COPE's Code of Conduct is not, however, an effective mechanism. Furthermore, COPE stated it would take no action whatsoever, if the EJCP rejected COPE's recommendation.

The mounting evidence of systematic attempts by commercial interests to corrupt the literature cannot be ignored, states the British Medical Journal (BMJ) [28]. The problem is so serious that the BMJ has adopted a policy of zero tolerance on education articles with financial links to industry.

Yet, as the above examples show, when authors or journals violate COI requirements, no accountability mechanism is in place. Without accountability, COI disclosure requirements lack credibility.

When COPE receives complaints of violations of its Code of Conduct, COPE acts "as a neutral third party, with the overall aim that airing of these concerns will lead to an improvement in the understanding and practice of publication ethics more widely." COPE also protects its member journals with anonymity, when it reports the cases on its website. There is no transparency and no public accountability.

In addition to using an internal, voluntary approach, comparable to corporate Codes of Conduct, COPE underlines its lack of resources to handle complaints: "complainants, journals and publishers should understand that COPE is run by a voluntary council, and complaints are just one of a large number of activities undertaken by the council." [9].

Thus, a handful of COPE volunteers deal with complaints of ethical violations on the edges of their spare time. The evidence clearly demonstrates that ensuring ethical publishing standards is not a priority of the scientific community.

COPE describes its role as being "a forum for editors and publishers of peer-reviewed journals to discuss all aspects of publication ethics." This is a valuable role, but exposes the crux of the problem. Neither the scientific community nor the publishing community has established an effective mechanism to deal with the COI issue. While hundreds of millions of dollars are spent on scholarly studies, virtually no funds are dedicated to upholding ethical standards and keeping the field honest. Yet, as the BMJ and UNESCO point out, this is a key public policy challenge of our times and poses a significant threat to human and environmental health.

These are not abstract issues. Countless lives have been destroyed because scientists, with undisclosed industry ties, have abetted endless industry subterfuge by creating doubt over the evidence. The strategy invented by the asbestos and tobacco industries has been appropriated by numerous other industries. In addition to the human tragedy, the economic costs caused by distorted scientific research of this kind are huge.

A recent editorial in Nature noted: "Transparency is the best defense against the purchase of undue influence by those with the most financial clout. In areas where tough standards are needed to protect public health, and powerful and wealthy interests have a financial incentive to water down these standards, such transparency is more 
than desirable-it is essential, and history demonstrates that." [29].

The problem is widespread and serious. Margaret Chan, Director-General of the World Health Organization (WHO), states that: "Research, evidence, and information are the foundation for sound health policies, for monitoring the impact, and for ensuring accountability. They keep us on track." She then points out that "even the very best scientific evidence can have less persuasive power than corporate lobbies [30].” A major global problem, notes Chan, is the fact that industries fund research geared to create doubt and prevent needed action to protect public health. Industry suppression of scientific data creates misinformation and skews priorities for research and public health interventions, says the WHO, which has called for action to stop this abuse [31]. The failure of the scientific community to take effective action to address conflict of interest has serious repercussions for public health policy. Faced with this void, government scientists, who have less freedom to act than other scientists, are challenging the censorship and distortion of research that conflicts with agribusiness industry interests. Public Employees for Environmental Responsibility, for example, representing local, state and federal researchers in the U.S., have filed a legal petition to require the U.S. Department of Agriculture to adopt policies to prevent "political suppression or alteration of studies and to lay out clear procedures for investigating allegations of scientific misconduct" [32].

Faced with the same problems of suppression and distortion of scientific research, government scientists in Canada are seeking to protect scientific integrity through collective bargaining. The Professional Institute of the Public Service of Canada, representing 15,000 federal government scientists, engineers and researchers has tabled a proposal that would obligate the government to negotiate scientific integrity policies [33].

\section{Call for action}

These are welcome but makeshift initiatives. The scientific community has created self-educational, professional mechanisms, such as COPE and WAME. What is urgently needed is that the scientific community create a practical mechanism whose purpose is to provide transparency, oversight and accountability to help stop the contamination of the scientific literature by undisclosed COI.

- Leaders in the scientific community with an impeccable track record of commitment to ethical standards should launch an initiative to set up an independent, effective and credible mechanism, such as a Center for Monitoring and Implementing Publication Ethics. It would take responsibility to investigate complaints, call for appropriate action and report publicly. Even a small Center, set up by respected scientists, would make a difference in creating transparency and accountability.

- A Center that monitored and publicly reported contraventions would impact a journal's and a scientist's credibility. Amnesty International does not have enforcement powers; but its monitoring and public reporting role has great impact.

- The Impact Factor of journals should include contraventions of COI disclosure requirements reported by the Center. Even journals with loose ethical standards would take this consequence seriously.

- COPE, ICMJE, WAME and other organisations and agencies should provide funds (perhaps $5 \%$ of their budget) to the Center, since it will be playing a critical role to implement the fundamental goals to which these organisations are committed. If necessary, a special "publication ethics implementation fee" could be charged to members. If the scientific community is not willing to put resources into ethical quality control, then they will send a clear message that they have no serious commitment to ethical standards.

- The leadership committee should examine previous initiatives such as the Integrity in Science Project, operated by the Center for Science in the Public Interest, which monitored the scientific literature for failure to disclose COI and maintained an open database of scientists' ties to industry.

- Institutions, such as the National Library of Medicine, that appear to confer credibility via listing studies, as well as government committees and agencies, such as the Environmental Protection Agency and the Occupational Safety and Health Administration, universities and professional societies, must adopt a strict policy requiring public COI disclosure and specifying consequences for violations, such as exclusion from future participation or placement on a list of unsatisfactory $\mathrm{COI}$ disclosure conduct.

- The proposed Ethics Centre should play a leadership role in monitoring and reporting how well, or how badly, government agencies, professional societies, universities and journals are requiring and enforcing ethical standards. It could be a much needed, credible voice calling for practical and effective changes, where systemic and repeated problems exist.

- Opportunities to develop practical solutions should be seized, such as funding currently offered by the Office of Research Integrity, US Department of Health and Human Services, for conferences or workshops to "produce tangible outcomes" towards research integrity compliance [34]. 
- A campaign could be launched calling for $1 \%$ of all research funding to be dedicated to ethical quality control carried out by the proposed Ethics Centre. As well as monitoring and reporting, the Centre would thus be able to fund independent, public interest research to document significant ethical failures in the current system, such as fraudulent peer review mechanisms [35], and propose practical solutions. Presently, these egregious problems are dealt with in an ad hoc, random manner.

- The Centre would be able to address other instances of conflicting interests, such as the fact that scientists' career opportunities may be affected by their ability to bring in grants or research contracts to their university [36].

- The leadership committee should draw on the expertise of individuals and organisations who have successfully implemented effective, credible accountability mechanisms to protect the public interest. Various models could be examined-Research Integrity Offices set up by universities; Ombudsman offices set up by governments. Sometimes these models are deliberately created to be weak. However, reliable knowledge and practical models exist as to how to make them effective.

\section{Conclusion}

It is not beyond the capability of the scientific community to take practical action on the problem of COI. Above are some examples of action that could be taken. To fail to act is a betrayal of public trust and scientific integrity.

\begin{abstract}
Abbreviations
AIRC: Italian cancer research association; $\mathrm{AOH}$ : Annals of occupational hygiene; BMJl: British medical journal; BPA: Bisphenol A; COl: Conflict of interest; COPE: Committee on publication ethics; COPM: Current opinion in pulmonary medicine; CRT: Critical reviews in toxicology; EJCP: European journal of cancer prevention; GP: Georgia pacific corporation; ICA: International chrysotile association; ICMJE: International Committee of Medical Journal Editors; IJERPU: International Journal of Environmental Research and Public Health; WAME: World Association of Medical Editors; WHO: World Health Organization.
\end{abstract}

\section{Competing interests}

KR works pro bono in the field of science, ethics and public health. She receives no funding, payments or benefits for her work. She pays costs, such as the publication cost of this commentary, herself. She has no competing interests to declare.

\author{
Acknowledgments \\ I express my appreciation to Leslie London and Bruce Lanphear for their \\ helpful comments and suggestions.
}

Received: 26 January 2015 Accepted: 21 May 2015

Published online: 30 May 2015

\section{References}

1. UNESCO Science Report. Growing concern about conflict of interest in scientific journals. 2010. p. 48. Publisher full text.
2. Goozner M, Caplan A, Moreno J, Barnett S, Kramer T, Babor TF, et al. A common standard for conflict of interest disclosure in addiction journals. Addiction. 2009;104:11

3. Vom Saal FS, Welshons WV. Large effects from small exposures. II. The importance of positive controls in low-dose research on bisphenol A. Environ Res. 2006;100(1):50-76.

4. International Committee of Medical Journal Editors, ICMJE Form for disclosure of potential conflicts of interest. http://www.icmje.org/conflictsof-interest/. Accessed 20 May 2015.

5. World Association of Medical Editors, Conflict of interest in peer-reviewed medical journals. http://www.wame.org/about/conflict-of-interest-in-peerreviewed-medical. Accessed 15 Jan 2015.

6. 2nd World Conference on Research Integrity, July 2010, Position Statement, Responsible research publication: international standards for authors. http:// publicationethics.org/files/International\%20standards_authors_for\% 20website_11_Nov_2011.pdf. Accessed 20 May 2015.

7. Committee on Publication Ethics, Press Release, Dec. 12, 2011, Global standards for authors and editors tackle thorny issues such as research bias and misleading publicity. http://publicationethics.org/files/International\% 20standards\%20PRESS\%20RELEASE\%20December\%202011\%20_0.pdf. Accessed 20 May 2015

8. World Association of Medical Editors, The principles of transparency and best practice in scholarly publishing. December 2013. http://www.wame. org/News/Details/2. Accessed 15 Jan 2015.

9. Committee on publication ethics, code of conduct and best practice guidelines for journal editors. http://publicationethics.org/resources/codeconduct. Accessed 15 Jan 2015.

10. Committee on publication ethics, how COPE handles submitted concerns about its members. http://publicationethics.org/complaints-and-concernsabout-our-members. Accessed 15 Jan 2015.

11. Sheehan PJ, Brorby GP, Berman DW, Bogen KT, Holm SE. Chamber for testing Asbestos-containing products: validation and testing of a re-created chrysotile-containing joint compound. Ann Occup Hyg. 2011;55(7):797-809. Publisher full text

12. Berman DW, Brorby GP, Sheehan PJ, Bogen KT, Holm SE. More on the dynamics of dust generation: the effects of mixing and sanding chrysotile, calcium carbonate, and other components on the characteristics of jointcompound dusts. Ann Occup Hyg. 2012;56(7):852-67. Publisher full text

13. Michaels D. Doubt is their product: how industry's assault on science threatens your health. Oxford: Oxford University Press; 2008.

14. Matter of New York City Asbestos Litig. 2013 NY Slip Op 04127. N.Y. App Div, 1st Dept, June 6, 2013. http://www.nycourts.gov/reporter/3dseries/ 2013/2013_04127.htm. Accessed 15 Jan 2015.

15. Seixas NS. Protecting our science. Ann Occup Hyg. 2013;57:963-5. Publisher full text.

16. Bernstein DM. The health risk of chrysotile asbestos. Curr Opin Pulm Med. 2014;20:366-70

17. Current opinion in pulmonary medicine, authorship responsibility, disclosure, and copyright transfer form. http://edmgr.ovid.com/copm/ accounts/copyrightTransfer.pdf. Accessed 20 May 2015.

18. Ruff K. Letter to Burgess I, Publisher, Current Opinion in Pulmonary Medicine, Wolters Kluwer, June 22, 2014. http://www.rightoncanada.ca/wpcontent/uploads/2014/06/Complaint-to-publisher-Current-Opinion-inPulmonary-Medicine.pdf. Accessed 15 Jan 2015.

19. Bernstein D, Dunnigan J, Hesterberg T, Brown R, Velasco JAL, Barrera R, et al. Health risk of chrysotile revisited. Crit Rev Toxicol. 2013;43:154-83. Publisher full text.

20. Critical reviews in toxicology, declaration of interest. http:// informahealthcare.com/userimages/ContentEditor/1408358936100/ BTXC_IFAs\%20lthenticate.pdf. Accessed 15 Jan 2015.

21. Ruff K, Bonnier-Viger Y, Turcotte F, Paek D, Zigby J. Letter to Roger McClellan, Editor in Chief, Critical reviews in toxicology, November 25, 2013. http://www. isde.org/asbestos_ruff.html. Accessed 15 Jan 2015.

22. Goswami E, Craven V, Dahlstrom DL, Alexander D, Mowat F. Domestic asbestos exposure: a review of epidemiologic and exposure data. Int J Environ Res Public Health. 2013;10:5629-70. Publisher full text.

23. La Vecchia $C$, Boffetta $P$. Role of stopping exposure and recent exposure to asbestos in the risk of mesothelioma. Euro J Cancer Prev. 2012;21(3):227-30

24. European Journal of Cancer Prevention, Conflicts of interest. http://edmgr. ovid.com/ejcp/accounts/ifauth.htm. Accessed 15 Jan 2015. 
25. LaDou J, Zigby J, Egilman D, Frank E, Pocekay E, Ruff K, et al. Complaint to committee on publication ethics, March 12, 2014. http://www.rightoncanada. ca/wp-content/uploads/2014/06/Complaint-to-COPE-March-12-2014.pdf. Accessed 15 Jan 2015.

26. Virginia Barbour, Chair of COPE. Letter to Editor and Publisher, European Journal of Cancer Prevention. 2014. http://www.rightoncanada.ca/wpcontent/uploads/2015/01/Message-from-COPE-October-6-2014.pdf. Accessed 15 Jan 2015.

27. Role of stopping exposure and recent exposure to asbestos in the risk of mesothelioma. Erratum. Euro J Cancer Prev. 2015;24:68. Publisher full text

28. Chew M, Brizzell C, Abbasi K, Godlee F. Medical journals and industry ties: zero tolerance on education articles with financial links to industry. BMJ. 2014;349:g7197. Publisher full text.

29. Full disclosure. Regulatory agencies must demand conflict-of-interest statements for the research they use. Nature. 2014;507:8. Publisher full text.

30. Chan M. Address to the sixty-sixth world health assembly, Geneva, Switzerland, 20 May 2013. http://www.who.int/dg/speeches/2013/world_ health_assembly_20130520/en/index.html. Accessed 15 May 2015.

31. WHO demands disclosure of all clinical trial results, Reuters, April 14, 2015. http://www.theglobeandmail.com/life/health-and-fitness/health/whodemands-disclosure-of-all-clinical-trial-results/article23960309/. Accessed 15 Jan 2015.

32. Gillam C. Reuters, environmental group seeks greater protection for USDA scientists, March 27, 2015. http://www.businessinsider.com/r-environmentalgroup-seeks-greater-protection-for-usda-scientists-2015-3. Accessed 15 May 2015.

33. Professional Institute of the Public Service of Canada, Federal Government Scientists Seek to Protect Scientific Integrity Through Collective Bargaining, Ottawa, December 3, 2014. http://www.pipsc.ca/portal/page/portal/website/ news/newsreleases/news/12032014. Accessed 15 Jan 2015.

34. Office of the Assistant Secretary for Health, announcement of the anticipated availability of funds for research conferences on research integrity, 02/11/2015. http:/www.grants.gov/web/grants/search-grants, html?keywords=IR-ORI-15-002. Accessed 15 May 2015

35. Dyer O. Major publisher retracts 43 papers, alleging fake peer review. BMJ. 2015;350:h1783.

36. Resnik DB. Science and money: problems and solutions. J Microbiol Biol Ed. 2014:159-161. Publisher full text.

\section{Submit your next manuscript to BioMed Central and take full advantage of:}

- Convenient online submission

- Thorough peer review

- No space constraints or color figure charges

- Immediate publication on acceptance

- Inclusion in PubMed, CAS, Scopus and Google Scholar

- Research which is freely available for redistribution 